\title{
METHODS TO DESIGN A GUIDED TOWER CONCERNING DYNAMIC BEHAVIOUR
}

\author{
Cecília Mendonça ${ }^{1}$ and Rui Carneiro de Barros $^{2}$ \\ ${ }^{1}$ Faculdade de Engenharia da Universidade do Porto \\ Rua Dr. Roberto Frias, s/n 4200-465 Porto, Portugal \\ e-mail: ceciliamen@gmail.com \\ ${ }^{2}$ Faculdade de Engenharia da Universidade do Porto \\ Rua Dr. Roberto Frias, s/n 4200-465 Porto, Portugal \\ e-mail: rcb@fe.up.pt
}

Keywords: Guyed tower, design, dynamic action, P- $\Delta$ effect, geometric non-linearity.

Abstract. The work presented in this paper pretends to structure the main concepts associated with the design of a guyed tower. In this context, are presented the theoretical foundations and the essential steps for the various methods of analysis.

This topic is therefore of major interest for Metalogalva (Trofa, Portugal), with which the authors collaborate and interact, since this industry complex of metallic constructions is also involved in the design and construction of tall telecommunication towers and pole structures.

Two dynamic actions are essential for the guyed tower design: The gust effect of wind and the action of earthquakes.

Therefore this paper presents various considerations and topics involved in the modeling of a $185 \mathrm{~m}$ height guyed tower, that enable to characterize their structural response. Since this is a slender structure it is was necessary to take into account the effects of second-order P-A analysis and also the nonlinear behavior of cables. 


\section{INTRODUCTION}

Guyed towers are comprised of a very slender mast supported laterally by inclined and in tension cables, which are anchored in concrete foundations. This setting appears as an economical option to self-supporting towers. However, its behavior is generally nonlinear and therefore is complicated to study and describe. The simplifications made and the approximate models used in their design over the years, often unjustified, led to the collapse of many structures.

For the study of the dynamic behavior of the guyed tower it is really important to understand how it reacts to the wind and to an earthquake. Figure 1 shows typical normalized spectral densities of wind and earthquake actions, where average frequencies of concern for wind and earthquake actions are also emphasized. As described, these two dynamic actions excite quite differently any type of tall (and low) structures.

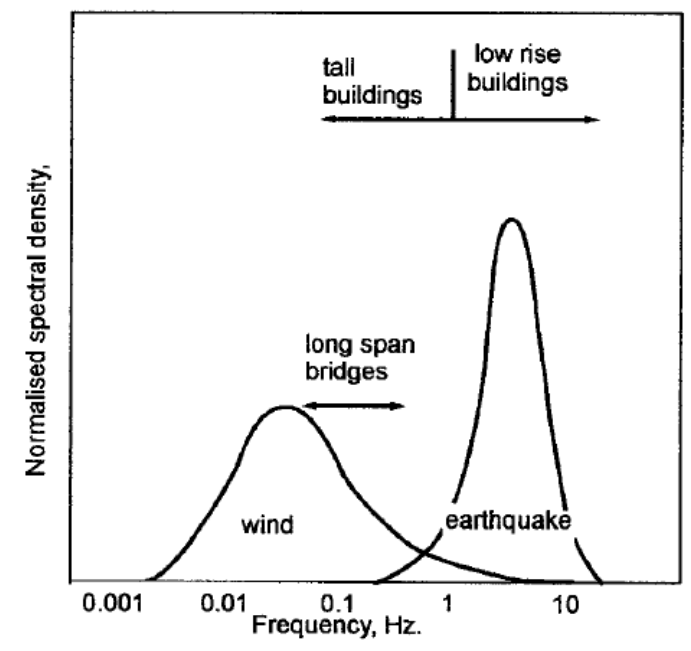

Figure 1: Dynamic excitation frequencies of structures by wind and earthquake. HOLMES [1]

The natural frequencies of truss structures are between 0,5 a $3 \mathrm{~Hz}$. When the masts are very flexible it is essential to study the dynamic behaviour in the first mode response due wind action, as well as the contribution of the second degree P- $\Delta$ effect related to structural instability.

The resonant response of slender structures becomes important when the natural frequency of the structure is below $1 \mathrm{~Hz}$ as Carril [2]. Between the two dynamic actions considered for this study on guyed towers, the wind is generally the controlling design action in this kind of structures.

\section{DYNAMIC ACTIONS}

\subsection{Wind}

The wind speed varies with height and its variation in time varies with the type of ground where it is deployed. The wind action is represented by a simplified set of pressures or forces whose effects are equivalent to the effects of turbulent wind. Ferreira et al.[3]

The generalized forces of wind on the masts can be characterized by quasi-static and dynamic components. Both forces and the displacements associated depend primarily on the fundamental mode and frequency and its damping. 
The quasi-static behavior and the time-varying behavior of these pole masts structures occurs along-the-wind (that is, in the direction of propagation of the wind) and is due to the addition of a constant wind pressure with a non-permanent gust pressure. The purely dynamic vibratory behavior of the pole-masts occurs in the transverse direction of propagation of wind (across-the-wind) and is due to the aerodynamic phenomenon of vortex shedding at the critical wind speed.

\subsection{Standards}

The reference standards used in the study of the behaviour of lattice towers (fixed or guyed) subjected to wind are the British Standard BS 8100 [4] American Standard ASCE [5] the German standard DIN 4131 [6] and European standard EN1991-1-4 [7].

The purely dynamic behaviour of masts occurs mainly in the transverse direction of the wind. Based on Annex E of the standard [7] and Barros[8]. One may check the elements of the structure to vortex shedding and ovalling.

The force applied to the model was obtained following the steps described in [7].

The characteristic values of the wind actions calculated in EN 1991-1-4 present an annual probability of being exceeded (2\%) equivalent to an average recurrence period of 50 years. The purely dynamic behavior of masts occurs mainly in the transverse direction of the wind (across-the-wind).

The mast structure under analysis and design verifications is a $185 \mathrm{~m}$ height tall guyed tower, with structure and cables layout detailed in Fig. 2, located in Lisbon area of soil type D Mendonça, C.[9]
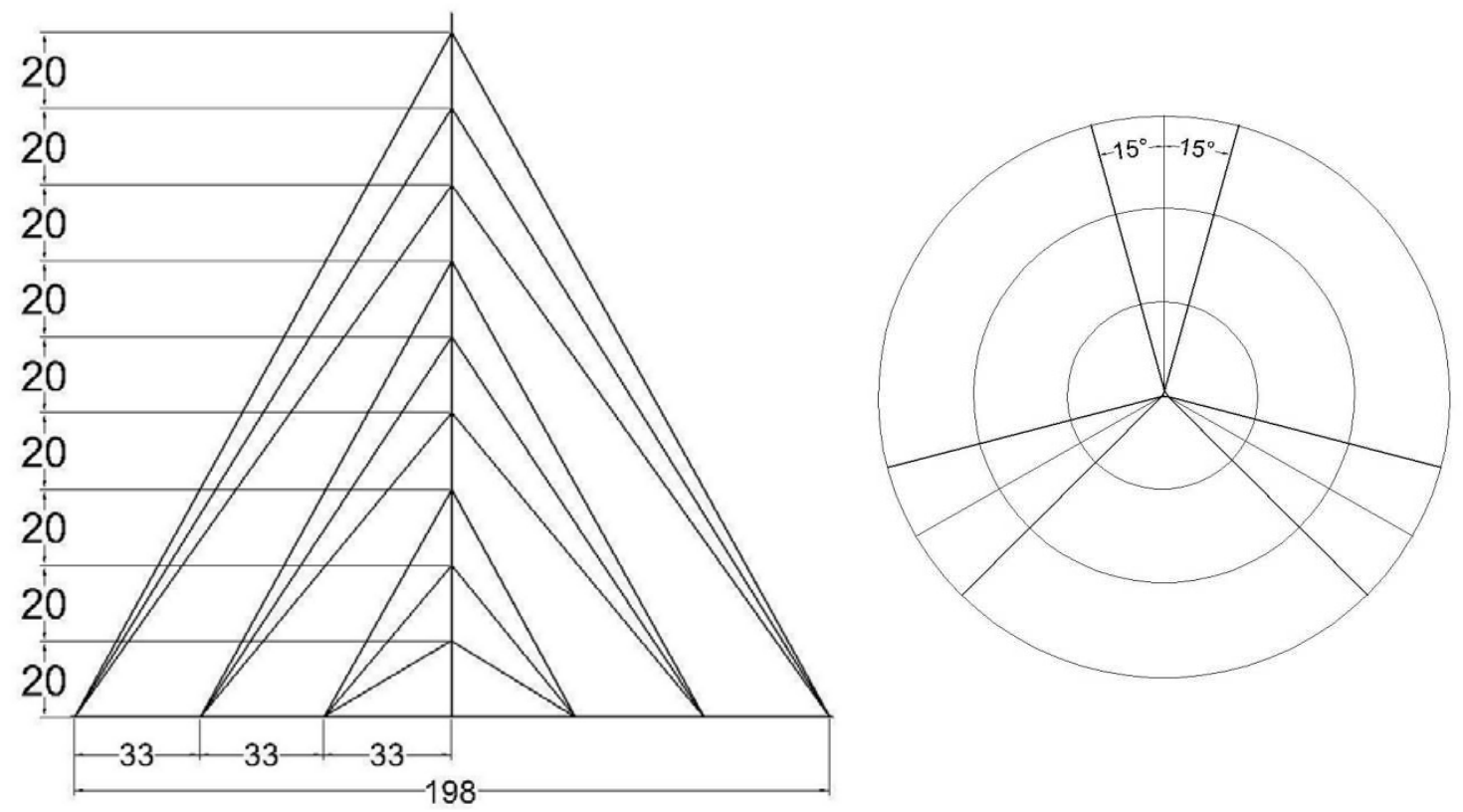

Fig. 2 - Layout (elevation and plan) of the guyed tower $185 \mathrm{~m}$ height

Based on Annex E of EN 1991-1-4, equation (1) and on details in [7], it is possible to evaluate the forces acting on a specific guyed tower model (Fig. 3) and access the mast structural response to vortex shedding as well as ovalization, Zar and Chu[10]. 


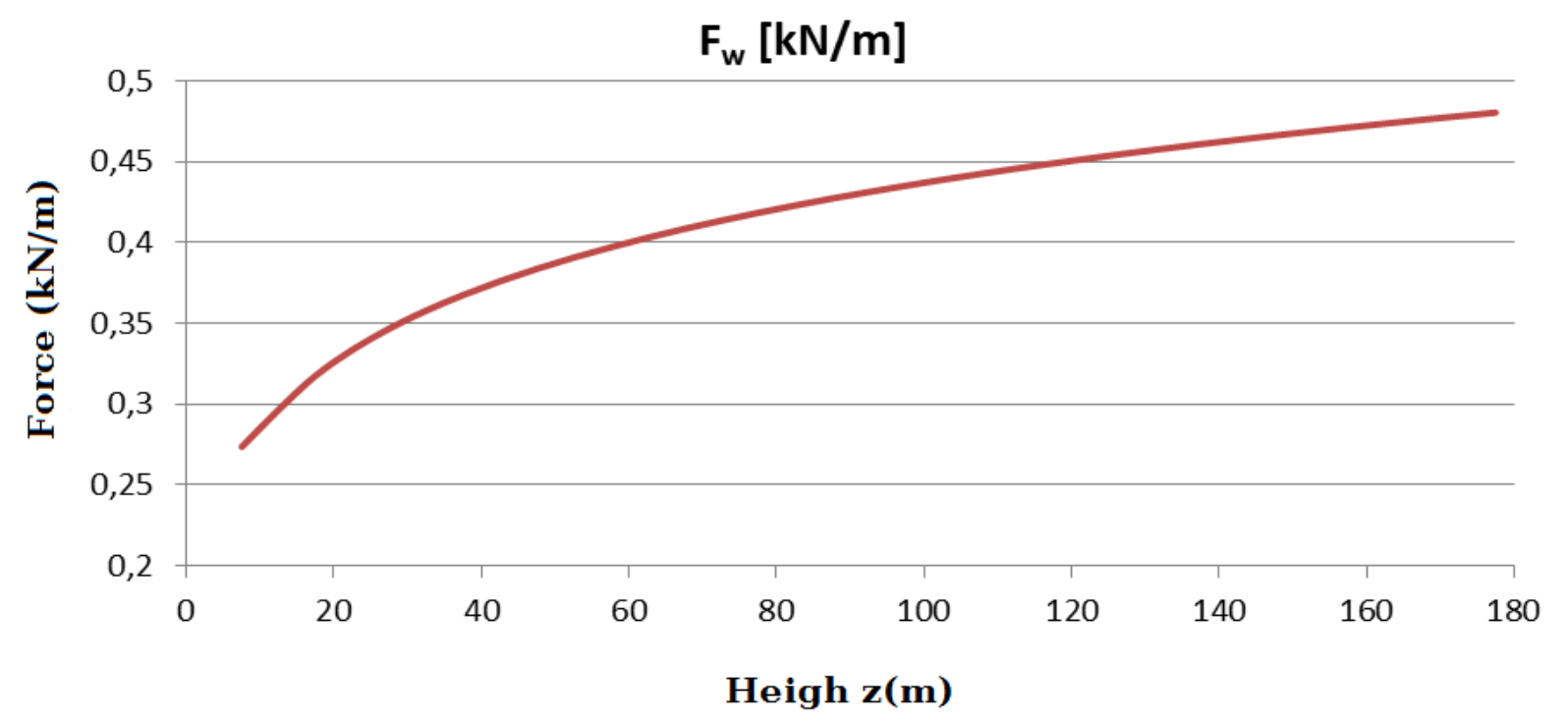

Fig. 3 - Force of the wind o the $185 \mathrm{~m}$ guyed tower mast $(\mathrm{kN} / \mathrm{m})$

\subsection{Earthquakes}

\subsubsection{Spectral Analyses}

According to Chopra [11] when analyzing the response of a general structure to seismic action, the equation of motion of the multi-degree-of-freedom structure is:

$$
m \ddot{u}_{\text {total }}+c \dot{u}+k u=0
$$

Where $\mathrm{m}$ is the mass, $\mathrm{c}$ is damping, $\mathrm{u}$ is the displacement and $\mathrm{k}$ is the stiffness of the structure. The total displacement $u_{\text {total }}=u^{t}$ is equal to the displacement of soil $u_{g}(t)$, plus the relative displacement of the structure $u(t)$.

$$
u^{t}=u+u_{g}
$$

The seismic movement only causes a dynamic response because the inertia forces depend on the total displacement of the structure (in fact they are expressed in terms of the total acceleration), while the elastic forces and damping depend only on the relative motion.

$$
m \ddot{u}^{t}+c \dot{u}+k u=0 \leftrightarrow m\left(\ddot{u}+\ddot{u}_{g}\right)+c \dot{u}+k u=0 \leftrightarrow m \ddot{u}+c \dot{u}+k u=-m \ddot{u}_{g}
$$

From equation (3), it may be inferred that the structure is acted upon by the seismic force that is defined as $F(t)=m \ddot{u}_{g}(t)$.

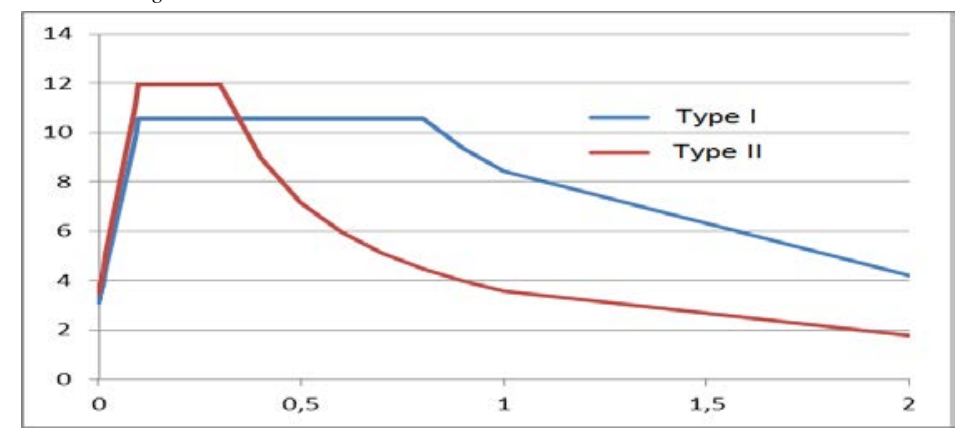

Fig. 4 - Acceleration response spectra for $\xi=0.05$ (Lisbon area, soil type D) 
To design the structure to seismic action two norms were used: the Portuguese regulation RSA [12] and Eurocode 8.[13,14]

\subsubsection{Time domain analysis for a given earthquake}

The use of a time domain analysis is interesting since it allows the input of scaled ground accelerations based upon time-histories of several earthquakes (recorded or synthetically generated). Since earthquakes occur with different frequencies, it is possible that a given earthquake has the ability to excite a given structure much more than others.

When using the information of past recorded earthquakes of certain frequency content, these accelerations can be applied at the structure ground-site after normalizing the information of these earthquakes by the PGA (Peak Ground Acceleration) at the site; the later is associated with a certain recurrence period and statistical distribution of earthquakes.

The time histories and associated data of earthquakes used in the time domain analyses of the guyed tower were taken from the site of the Pacific Earthquake Engineering Research Center , PEERC [15]. The present design study used data from four earthquakes: Çaldiran (Turkey, 1976), Loma Prieta (USA, 1989), Kobe (Japan, 1995) and Chi-Chi (Taiwan, 1999). It is also noticeable that the frequency band of these earthquakes is mainly $1 \mathrm{~Hz}$ to $10 \mathrm{~Hz}$ (Fig. $6)$.

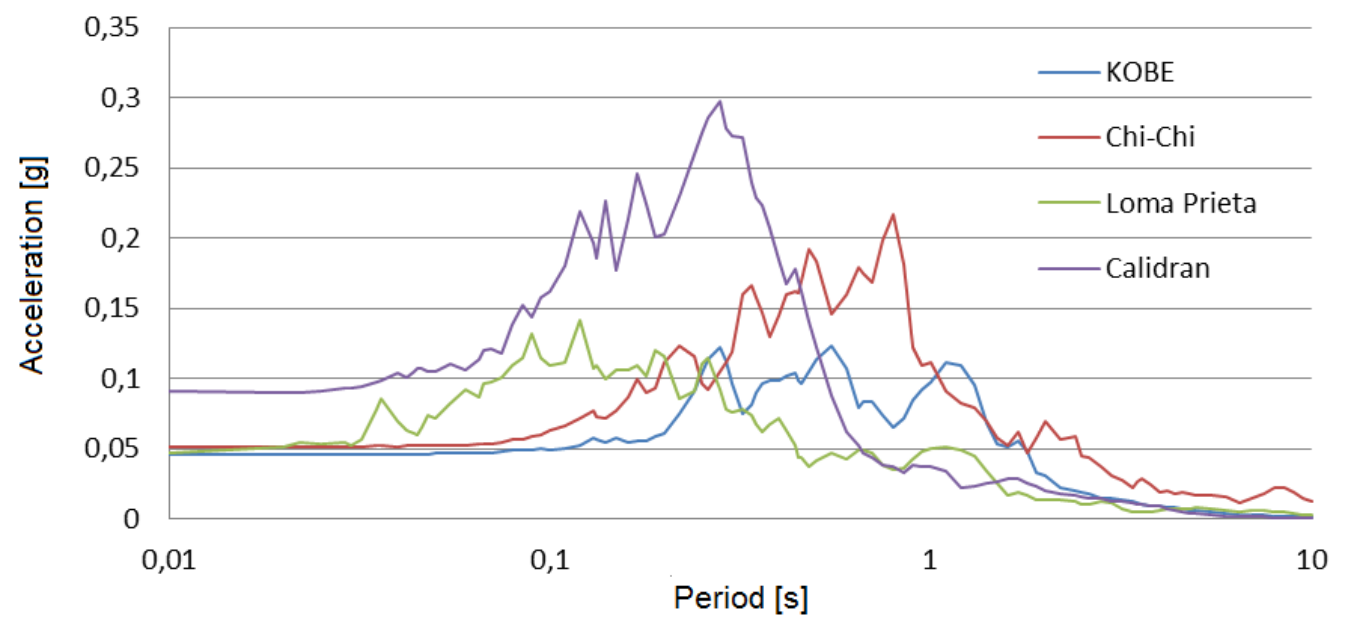

Fig. 5 - Band of frequencies of the four earthquakes

\section{MODELING}

As a first approach to the design of a guyed tower, Gantes [16] suggest a simplified equivalent beam model with springs to simulate the cables that constitute an interesting initial assessment. It should be used to frame the initial structural characteristics of the guyed tower so that it is possible to model it in any finite element program.

\subsection{Requirements}

The guyed towers designed for telecommunication have to meet service requirements of the telecommunication devices themselves, since a slight misalignment of the satellites may result in loss of signal, which may lead to poor quality of service for thousands of customers. 
Section 3.8.2 of the American standard TIA $222[17,18]$ specifies a maximum horizontal displacement of $3 \%$ of the height of the guyed tower structure; wherefore for lattice structures the limiting value of the horizontal displacement is only $1.5 \%$ of the tower height.

TIA 222 also specifies a maximum value for the rotation of the antennas of $4^{\circ} 00^{\prime} 00^{\prime \prime}$, which is also the limit imposed by Telebrás for VHF antennas. When it comes to broadcasting on UHF antennas Telebrás is more restrictive and imposes a maximum rotation of $1^{\circ} 40^{\prime} 00^{\prime \prime}$.

\subsection{Mast}

The analysis of more traditional tower masts proposes the modeling as a simple truss structure. As the links are not rigid, the structure appears more flexible than it actually is. To partially solve this problem, it resorts to the use of dummy bars. These prevent the occurrence of undesired degrees of freedom leading to the occurrence of mechanisms. The use of these bars, with very little axial stiffness, allows the structure to be stable nevertheless flexible and therefore enables analyses of the tower under design study using some software based upon the finite element method. Many manufacturers still rely on full-scale tests to verify that the results are as expected using a simpler truss model for design of the guyed tower.

Oliveira et al. [19] proposes a less conservative analysis method which combines threedimensional framed members with horizontal and diagonal lattice members, so it is not necessary to use dummy bars. It constitutes a better and more real approximation of the structural behavior.

\subsection{Cables}

The cables were modeled by existing cable element in SAP 2000 v15 [20]. The program models the cable as a catenary to represent the elastic behavior of a cable subjected to its own weight. Its behavior is nonlinear and takes into account the P- $\Delta$ effects as large displacements and large deformations are accounted for.

A cable without tension is not stable and has not an unique position, so all cables should be loaded. The Canadian standard CSA S37-01 [21] requires that the values of the initial tension in the cables should be between $8 \%$ and $15 \%$ of the final cable capacity.

The environmental temperature and the applied loads (namely due to wind and earthquake) can change the cable length. The effect of these changes is similar to changes of length of the undeformed cable with the exception that there is no change in self-weight.

An alternative model that can be programmed for the dynamic study of the cables was given by Desai and Punde [22] which obtained values very close to the analytical values available, and is very quick to apply. Also Bertero [23] and Naguib and El-Saad [24] state that one can not disregard the initial deflection, or the pressure exerted by the wind on the cable itself, which otherwise would reach different values in the order of $10 \%$ to $15 \%$.

Menin [25] also used the initial tension as $10 \%$ of the ultimate stress, designing the guyed tower from such hypothesis. As expected, and also as it can be seen by the results obtained by Naguib and El-Saad [24], the higher the value of the initial tension employed in the cables, the smaller the tower displacements would generally be. Naguib and El-Saad [24] program allows initial tensions up to $40 \%$ of the ultimate strength, which is beyond the control parameters adopted in this work and taken from the Canadian standard CSA S37-01 [21]. In this design study it was used an initial tension close to $10 \%$ of the ultimate stress. But if it would be needed an expeditious manner, without recourse to a FEM software or specific program, the one proposed by Bertero [23] is advised. 


\subsection{Load Cases Combinations}

The combinations used for the verification of the stress in the guyed tower structure were:

$$
\left\{\begin{array}{l}
Q 1: S=(1.35 \text { ou } 1) \times G+1.5 \times Q_{1}+0.9 \times Q_{2} \\
Q 2: S=(1.35 \text { ou } 1) \times G+0.9 \times Q_{1}+1.5 \times Q_{2} \\
C A: S=G+F_{\text {acidental }}+0.4 \times\left(Q_{1}+Q_{2}\right)
\end{array}\right.
$$

Where Q1 is a variable action based on wind overload, Q2 is the variable action based on temperature variation and CA is the accidental combination.

\section{ULTIMATE LIMIT STATES VERIFICATIONS}

For a structure the ultimate limit states that need to be considered are: loss of static equilibrium, internal failure of the structure, excessive deformation of the ground and fatigue. In a steel structure as the guyed tower the limit state referring to internal failure involves the resistance of cross sections, the resistance of the structure to instability.

The recommended values in EC3 for the partial safety factors are the following:

$$
\gamma_{M 0}=1.00, \gamma_{M 1}=1.00, \gamma_{M 2}=1.25
$$

The resistance of cross sections depends on the class of the section. The verification made using the elastic resistance is valid for all classes of sections, although for class 4 only the effective area is taken into account. For classes 1 and 2 the use of the plastic resistance is advisable, so that the solution achieved is economical.

\subsection{Axial Force}

Replacing the axial force $N$ of expression (5) for the maximal axial force $N_{\text {máx }}$ obtained from the load combinations one gets the minimal area needed Amin to support those actions.

$$
A_{\min }=\frac{N}{f_{y}}
$$

\subsection{Bending Moment}

Replacing the bending moment $M$ of expression (6) for the maximal bending moment $M_{\text {máx }}$ obtained from the load combinations, one gets $W_{p l, m i n}$ so that the section verifies for those actions.

$$
W_{p l y-\min }=\frac{M}{f_{y}}
$$

\subsection{Bending Moment and Axial Force interaction}

$$
\frac{M_{y}}{M_{p I} y}+\left(\frac{N}{N_{p I}}\right)^{2}=1
$$

4.4 Bending Moment and Shear Force interaction

$$
V_{p l_{2} r d}=\frac{A_{V z}}{\gamma_{M_{0}}} \frac{f_{y}}{\sqrt{3}}
$$

\subsection{Asymmetrical bending}

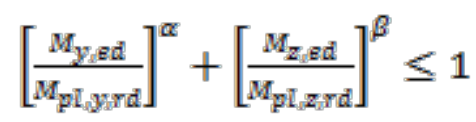




\subsection{Buckling effect}

Guyed Towers are a very slender structure so it's very important to avoid the loss of stiffness in the structure when it is subjected to high compressive stresses. This effect, known as tower global buckling leads to sudden failure of the structure by progressive and excessive lateral deformations.

Guyed towers are very slender structures, so it is very important to avoid the loss of stiffness in the structure when it is subjected to high compressive stresses. This effect, known as (tower global) buckling, leads to sudden failure of the structure The evaluation of all the Euler critical loads of each individual structural member (member buckling) is not a good approach to access the buckling capacity of the tower, when trying to describe what happens with more complex structures instead than the behavior a single column. The critical load of the guyed tower - Ncr - can be determined by a series of tests, simulating the degradation of the stiffness of the tower mast.

It is known that the general equilibrium equation of a structure analyzed by the displacement method is $F=F_{0}+K_{T} D$ where $K_{T}$ is the total stiffness (elastic stiffness, geometric stiffness contribution - positive for tensile members, negative for compressed members - and decrease in stiffness due to material non-linearity). In the vicinity of a previous state of stable equilibrium, the incremental equilibrium insures that:

$$
\Delta F=K_{T} \Delta D \quad \Rightarrow \quad K_{T}=\Delta F / \Delta D
$$

Generalizing this tangent total stiffness concept to the tower structure, and labeling Fx as a disturbing horizontal load applied on the top of the tower mast and $\mathrm{dx}$ as the tower resulting horizontal displacement in the same point, then the ratio $\mathrm{Fx} / \mathrm{dx}$ is an index or a measure of the transversal stiffness of the tower mast for each axial compressive load $\mathrm{N}$ applied to the mast.

A total of 15 individual computational load tests were performed in the tower model, with different vertical and horizontal forces, and the corresponding top lateral displacements were evaluated by tower structural analyses. A linear regression on the computational results obtained permits to determine computationally when the stiffness of the structure would vanish; in fact:

$$
\frac{F_{x}}{d_{x}} \approx a \lambda+b=0 \rightarrow \lambda=-\frac{b}{a}
$$

where $\lambda$ is the buckling load factor insuring null total stiffness of the tower at the onset of elastic instability.

\section{RESULTS}

\subsection{Natural vibration frequencies and vibrations modes}

The analyses of the natural vibration frequencies and mode shapes are very important for understanding the dynamic behavior of the structure, as well as for evaluating the effective modal masses and the percentage of these needed to access the response with desired accuracy. Even though the first mode of the $185 \mathrm{~m}$ height guyed tower under analysis has a very low frequency $(0.625 \mathrm{~Hz})$, it has almost no mass associated with that torsion mode. So it is expected that the next two natural frequencies of the guyed tower $\left(2^{\text {nd }}\right.$ and $3^{\text {rd }}$, equal by sym- 
metry) of $1^{\text {st }}$ (and $2^{\text {nd }}$ ) longitudinal bending mode along 2 perpendicular directions, would have significant effective modal masses vibrating close to $1 \mathrm{~Hz}$ natural frequencies.

Table 1 indicates the values and shapes of the natural frequencies $(\mathrm{Hz})$ and vibration mode shapes of the considered design case study of the guyed tower.

Table 1 - Vibration frequencies and mode shapes

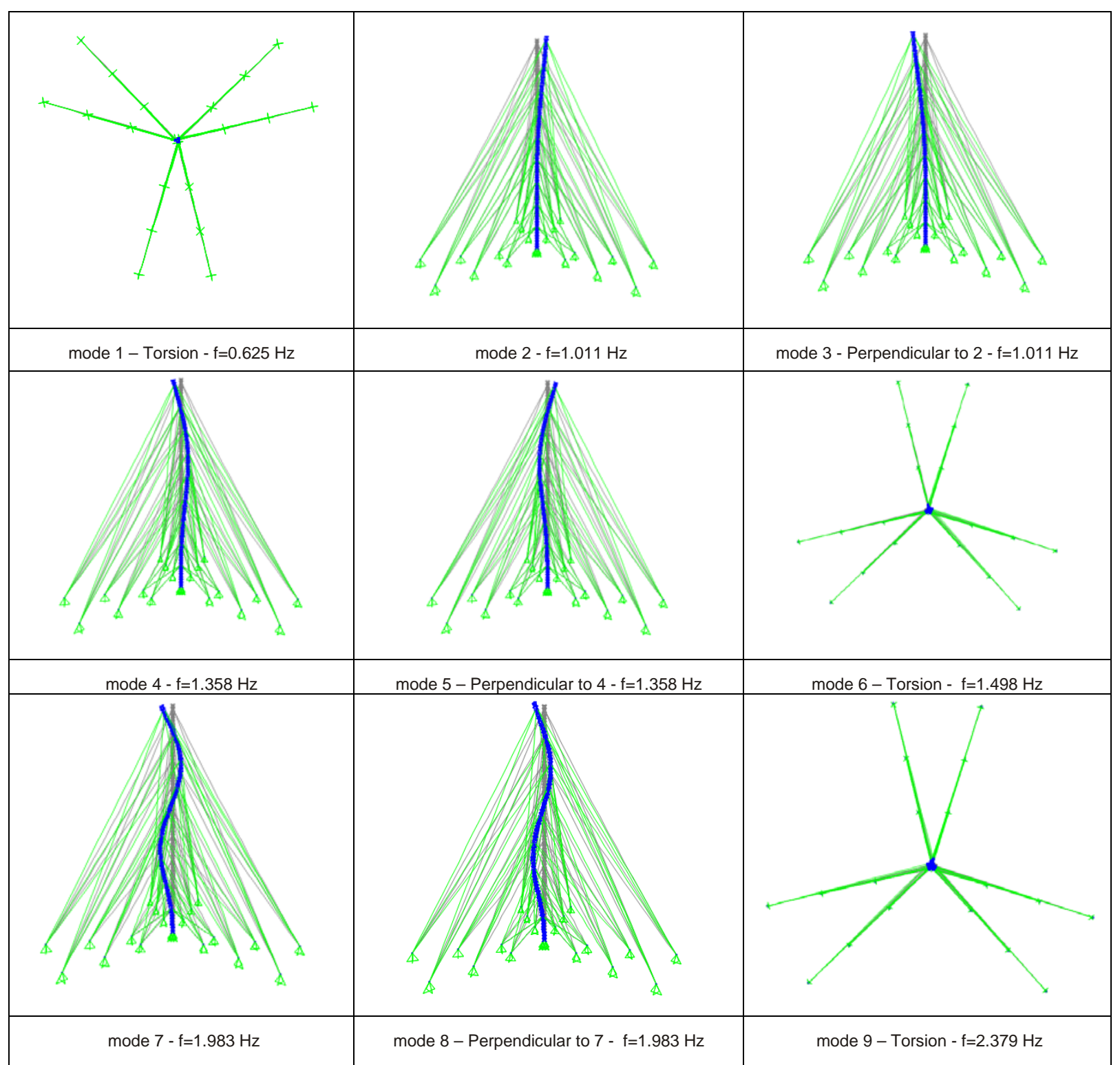




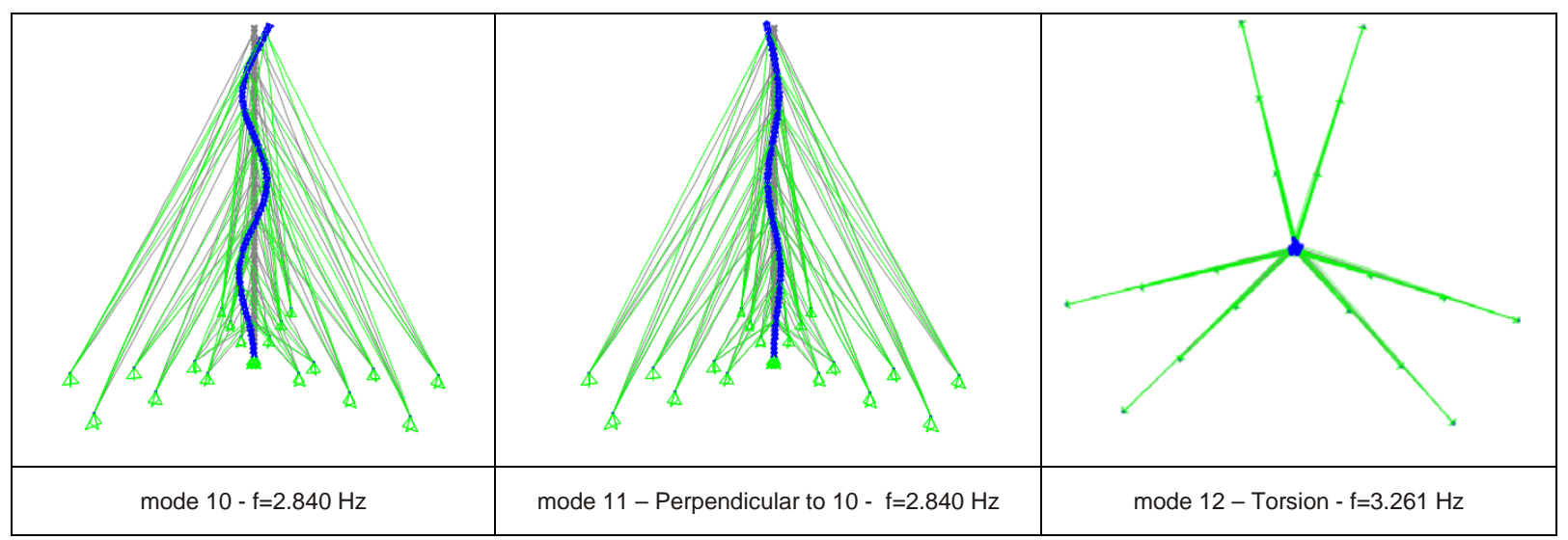

\subsection{Load Cases Combinations}

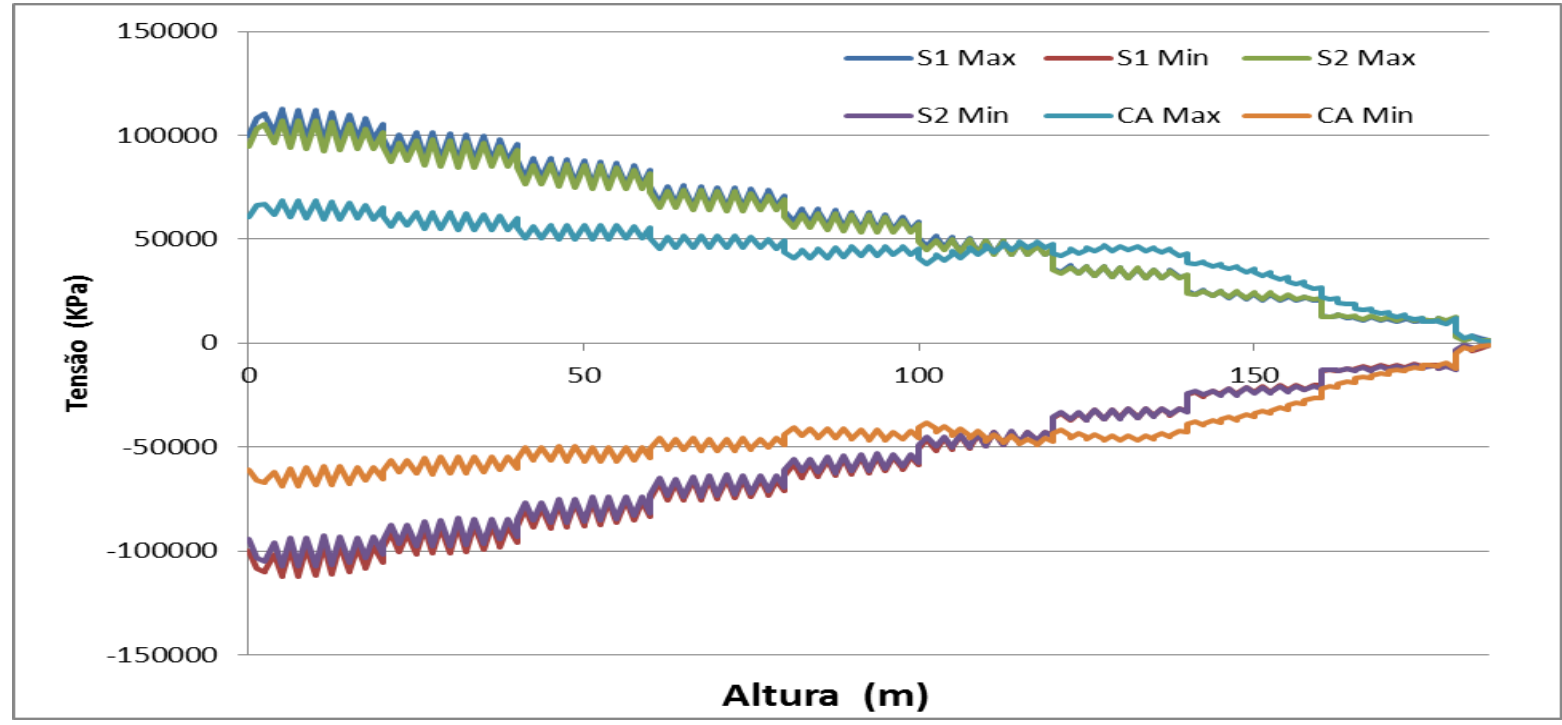

Fig. 6 - Load case combinations

One can see from this analysis that the most onerous load case combination is that of accidental earthquake load using spectrum given by Eurocode 8 for earthquake type 1; followed by the case of earthquake type 2 . The load case S1 appears in 3rd place.

However when individually examined (without load combinations) the wind load would undoubtedly be more demanding for the structure than the earthquake load alone.

\subsection{Overall Global Buckling}

The 15 load cases applied and the displacements resulting from such load disturbances are detailed in Table 5. As it can be seen, the stiffness index $F_{x} / d_{x}$ is getting closer and closer to zero. It can never hit zero, since the analysis program would return an error for having become unstable.

From a linear regression on the computational data (Fig. 8) the following equation is obtained:

$$
\frac{F x}{d x}=-12.789 \lambda+75.618
$$


For vanishing stiffness $F_{x} / d_{x} \rightarrow 0$, from which $\lambda_{c r}=75.618 / 12.789=5.912738$.

Multiplying the initial axial force (for axial load factor $\lambda=1$ ) by $\lambda_{c r}$, the value of $N_{c r}$ would be:

$$
N_{c r}=5.912738 \times 600 \mathrm{kN}=3547.643 \mathrm{kN}
$$

Table 5 - Determination of $\mathrm{N}_{\mathrm{cr}}$ of the guyed tower

\begin{tabular}{|c|cc|ccccc|}
\cline { 2 - 8 } \multicolumn{1}{c|}{} & \multicolumn{2}{c|}{1 Column } & \multicolumn{5}{c|}{3 Columns } \\
\hline Coad & $\mathrm{F}_{\mathrm{x}}{ }^{\prime}$ & $\mathrm{P}^{\prime}$ & $\mathrm{F}_{\mathrm{x}}$ & $\mathrm{P}$ & $\mathrm{d}_{\mathrm{x}}$ & $\mathrm{F}_{\mathrm{x}} / \mathrm{d}_{\mathrm{x}}$ & $\lambda$ \\
- & $\mathrm{kN}$ & $\mathrm{kN}$ & $\mathrm{kN}$ & $\mathrm{kN}$ & $\mathrm{M}$ & $\mathrm{kN} / \mathrm{m}$ & - \\
\hline 1 & 4 & 200 & 12 & 600 & 0,1952 & 61,48 & 1,00 \\
2 & 2 & 200 & 6 & 600 & 0,0945 & 63,49 & 1,33 \\
3 & 4 & 250 & 12 & 750 & 0,2139 & 56,10 & 1,67 \\
4 & 4 & 270 & 12 & 810 & 0,2223 & 53,98 & 1,80 \\
5 & 4 & 300 & 6 & 900 & 0,2361 & 25,41 & 2,00 \\
6 & 2 & 300 & 6 & 900 & 0,1145 & 52,40 & 2,00 \\
7 & 4 & 350 & 12 & 1050 & 0,263 & 45,63 & 2,33 \\
8 & 4 & 400 & 12 & 1200 & 0,1903 & 63,06 & 2,67 \\
9 & 2 & 400 & 6 & 1200 & 0,1441 & 41,64 & 2,67 \\
10 & 4 & 500 & 12 & 1500 & 0,3883 & 30,90 & 3,33 \\
11 & 4 & 600 & 12 & 1800 & 0,5434 & 22,08 & 4,00 \\
12 & 4 & 700 & 12 & 2100 & 0,8306 & 14,45 & 4,67 \\
13 & 4 & 800 & 12 & 2400 & 1,5091 & 7,95 & 5,33 \\
14 & 2 & 800 & 6 & 2400 & 0,9853 & 6,09 & 5,33 \\
15 & 4 & 820 & 12 & 2460 & 1,8657 & 6,43 & 5,47 \\
\hline
\end{tabular}

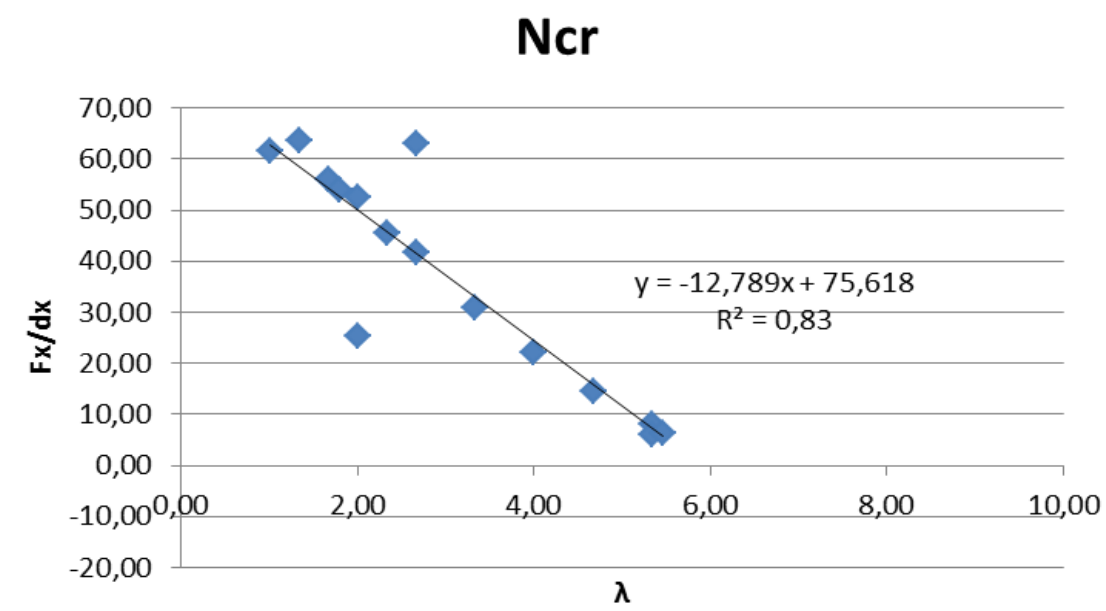

Fig.7 - Determination of $\mathrm{N}_{\mathrm{cr}}$ through linear regression of stiffness indexes from a numerical simulation 


\section{CONCLUSIONS}

Some relevant concepts and steps to design tall guyed towers were addressed, particularly those related to wind and seismic actions. The wind pressures were evaluated according to Eurocode 1 (EN 1991-1-4). The seismic actions were evaluated using RSA and also by Eurocode 8 (EN 1998-1-1 , EN 1998-6); for the design study case of the guyed tower mast, the seismic actions evaluated by EC8 are more severe than those evaluated by RSA, or even those evaluated by a time domain analysis of four historic earthquake records scaled by the PGA at the site (Lisbon area). The natural vibration frequencies and mode shapes were obtained using SAP 2000 v15. The ultimate limit states verifications were address. A general methodology for calculating the tower mast buckling load, also applicable to general complex structures, is applied.

\section{ACKNOWLEDGMENTS}

This work was co-participated by funds from the project "VHSSPOLES-Very High Strength Steel Poles” (Faculty of Engineering of the University of Porto, reference 21518) sponsored by the European Fund for Regional Development (FEDER) through COMPETE (Operational Program Competitiveness Factors - POFC). The Authors acknowledge the financial support and the opportunity to contribute to the development of the transmission towers testing site of Metalogalva (Trofa, Portugal).

\section{REFERENCES}

[1] Holmes, J.D. - Wind Loading of Structures. Spon Press, Taylor \& Francis Group, 2001.

[2] Carril JR., C. Análise Numérica e experimental do efeito dinâmico do vento em torres metálicas treliçadas para telecomunicaçõess. Dissertação de Doutoramento, Escola Politécnica da Universidade de São Paulo, 2000.

[3] Ferreira, N.A., Barros, R.C., Delgado, R. - Comparisons of a tall building wind response with and without a TMD. 3rd International Conf on Computational Methods in Structural Dynamics and Earthquake Engng (CompDyn 2011: \# 654), Corfu, 2011.

[4] BS 8100-3 - Lattice towers and masts. Code of practice for strength assessment of members of lattice towers and masts. British Standards Institute, London, 1999.

[5] ASCE Standard - Guide for the Dynamic Response of Lattice Towers. American Society of Civil Engineers, New York, 2000.

[6] DIN V 4131 - Steel Radio Towers and Masts. German Standard, 2008.

[7] EN 1991-1-4 - Ações em estruturas: Ações gerais - Ações do vento. LNEC, Lisboa, 2010.

[8] Barros, R. - Dimensionamento estrutural de mastros metálicos. Revista Internacional de Métodos Numéricos para Cálculo y Diseño en Inginiería, pp: 351-365, Spain, 2002.

[9] Mendonça, C.M.A. - Dimensionamento de torres espiadas de grande altura. Dissertação de Mestrado Integrado em Engenharia Civil, Faculdade de Engenharia da Universidade do Porto (FEUP), Porto, 2012. 
[10] Zar, M. e Chu, S. - Chimneys. In: E.H. Gaylord and C. N. Gaylord, Structural Engineering Handbook. McGraw-Hill Book Company, New York, 1979.

[11] Chopra, A. - Dynamics of Structures: Theory and applications to Earthquake Engineering. Pearson Education Inc., New Jersey, 2007.

[12] RSA - Regulamento de Segurança e Ações para Estruturas de Edifícios e Pontes, Diário da Républica, $1^{\text {a }}$ Série no 125, p. 1991, INCM, Lisboa, 1983.

[13] EN 1998-1-1 - Projecto de estruturas para resistência aos sismos - Parte 1: Regras gerais, acções sismicas e regras para edifícios. Eurocódigo 8, Norma Europeia, Bruxelas, 2010.

[14] EN 1998-6 - Design provisions for earthquake resistance of structures - Part 6: Towers, masts and chimneys. Eurocode 8, European Norm, Brussels, 2003.

[15] PEERC - Pacific Earthquake Engineering Research Center. Ground motion database, http://peer.berkeley.edu/peer_ground_motion_database , 2012.

[16] Gantes, C., Khoury, R., Connor, J.J., Pouangare, C. - Modeling Loading and Preliminary Design Considerations for Tall Guyed Towers. Computers and Structures, Vol. 49, No 5, pp: 797-805, 1993.

[17] TIA 222-F - Structural Standards for Steel Antenna Towers and Antenna Supporting Structures. Telecommunications Industry Association, American National Standard, Arlington VA, 1996.

[18] TIA 222-G - Structural Standard for Antenna: Supporting Structures and Antennas. Telecommunications Industry Association, American National Standard, Arlington VA, 2006.

[19] Oliveira, M.I.R., Silva, J.G.S., Vellasco, P.C.G.S., Andrade, S.A.L., Lima, L.R.O. Structural Analysis of Guyed Steel Telecommunication Towers for Radio Antenna, Journal of the Brazilian Society of Mechanical Sciences and Engineering, Vol XXIX, $\mathrm{n}^{\mathrm{o}}$ 2, pp: 185-195, Rio de Janeiro, 2007.

[20] SAP 2000 v15 - Integrated Software for Structural Analysis \& Design. Computers \& Structures Inc. (CSI), http://www.comp-engineering.com/products/SAP2000/sap2000.html Berkeley CA, 2012.

[21] CSA S37-01 - Antennas, towers and antenna-supporting structures. CSA Group, 2011.

[22] Desai, Y.M., Punde, S. - Simple model for dynamic analysis of cable supported structures. Engineering Structures, 23, pp: 271-279. Elsevier Science, Mumbai, 2001.

[23] Bertero, V - Amplification of stress and displacement in guyed towers. Journal of the Structural Division, ASCE, Vol 85 nº ST5, pp: 89-101, 1959.

[24] Naguib, M., El-Saad, A. - Effect of Initial Sag and Tension in Cables on Outcome Responses in Cable Structures. 2006

[25] Menin, R. - Análise Estática e Dinâmica de torres metálicas estaiadas. Dissertação de Mestrado, Faculdade de Tecnologia - Universidade de Brasília, 2002. 